\title{
Inaugural Dissolution Discussion Group Meeting
}

I am pleased to report the first meeting of the Dissolution Discussion Group (DDG) was a success. Although this group functions primarily as an interactive web site, members have an opportunity to participate in regional meetings throughout the year. This recent meeting was beld in Cary, North Carolina and as one of the three moderators I can report that as an inaugural meeting the accomplishments were unparalleled.

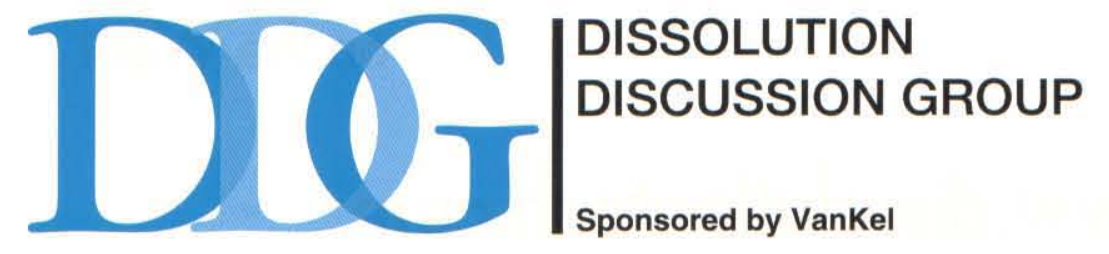

Our group was diverse with over 30 attendees representing all disciplines of dissolution. The group is comparable to the Stability Discussion Group with the addition of the interactive web based portion. Our agenda was aggressive, well maintained and all of our objectives were met.

During our review of the Mission statement we considered several refinements and agreed on the Mission as stated below. We also established bylaws for the organization.

\section{DDG Mission:}

The mission of the Dissolution Discussion Group (DDG) is to provide an independent forum to freely discuss the practical issues that challenge the pharmaceutical industry and affect the day-to-day task of developing, validating, and performing dissolution tests and related chemical analyses.

\section{DOG Bylaws:}

The following set of rules have been developed by the Dissolution Discussion Group (DDG) during the inaugural meeting on April 14, 1998 in Cary, North Carolina for the mutual benefit of its members and the regulation of its affairs.

1. Confidentiality: Specific ideas, examples and poll results are not to be associated with company names. Specific ideas, examples, and poll results are not to be associated with names of individuals. Proprietary information will not be discussed.

2. Attendees should be willing to participate in polls. Polls are vital to obtain percentages of participation in specific topics of discussion. Polls represent a percentage of attending DDG members and not a true representation of the industry.
3. Specific issues are not to be published. Primary topics along with poll results will be posted on the web on Meeting Notes Pages.

4. Attendees should share information they have obtained from other GMP related meetings and interaction with regulatory agencies. 5. We encourage a free exchange of ideas so all comments are welcome.

6. Individuals are not to criticize or be criticized for their beliefs, or point of views.

The DDG members then proceeded to vote on the top topics to discuss. These topics were generated from response on the web site. Three of these were discussed as a group (Method Development, Method Validation, and Calibration). Each area included a discussion of topics with polling and open comments. The web site (www.dissolution.com) lists in outline form the subjects covered under these three headings. Following the group discussions we broke into smaller "break out" groups to discuss the topics that did not make the top 3 list but nevertheless generated a lot of interest. These included: QC Issues, Regulatory Issues, Automation and Sparingly Soluble drugs. Again, the specific issues discussed are in outline form on the web site.

Finally the meeting concluded with a discussion on the DDG goals and Next Steps as listed below. It was agreed that another meeting would be held this year in New Jersey.* The dates will be October 8th and 9th. A European Chapter has also been established and is scheduled to meet in Brussels, Belgium on November 9th and 10th.

\section{DOG Goals:}

1. Provide Dissolution feedback to the Pharmacopoeia Forum (USP) and the Pharma Group

2.Provide forums for specific areas within dissolution

3. Share and disseminate information through the industry 
4. Utilize this resource to improve and expand our own laboratories

5. To be a resource on

(1) Method Development \& Validation;

(2) Calibration Issues;

(3) Regulatory Issues;

(4) Automation; and

(5) Instrument Enhancement

\section{Purpose}

This discussion group posting is for real time discussions of dissolution questions, suggestions and techniques. This in an open forum to encourage problem solving. Comments regarding suppliers, agencies, or participants and their companies should be avoided. The registration list will not be sold to any company.

\section{Disclaimer}

Comments made on this Web Site do not reflect the views of DDG as a group or its sponsors. No reprint or reproduction of any of the material within this discussion group is allowed without the permission of the sponsor.

\section{Netiquette}

Comments should be restricted to dissolution and solutions, not directed at specific companies, equipment, vendors or agencies. Any comment viewed as slanderous or inappropriate by the moderator will be deleted from the site.

This summary covers the business of the meeting. The DDG provides a great benefit to all of us involved in dissolution testing. As a result of my involvement in this first meeting and my experiences on the web page I now have a new resource with a wealth of untapped knowledge. I encourage everyone to sign on (its free and confidential). You will not only glean information for yourself but also gain satisfaction by helping fellow scientists around the world.

* To reserve your place at the next DDG Meeting in New Jersey (October 8th and 9th) call Vicki Kenyon at 1-800-229-1108. 